\title{
A angústia na formação do estudante de medicina
}

\author{
Distress in Medical Education
}

\section{PALAVRAS-CHAVE:}

-Estudantes de Medicina;

- Psicologia Médica;

-Estresse Psicológico.

\section{KEY-WORDS:}

-Students, Medical;

-Psychology, Medical;

-Stress, Psychological.

Recebido em: 09/11/2006

Reencaminhado em:23/03/2007

Aprovado em: 15/05/2007

$\left.7\right|^{\text {REVISTA BRASILEIRA DE EDUCAÇĊO MÉDICA }}$ $732(1): 7-14 ; 2008$

\author{
Alberto Manuel Quintana ${ }^{1}$ \\ Arnaldo Teixeira Rodrigues ${ }^{1}$ \\ Dorian Mônica Arpini ${ }^{1}$ \\ Luis Augusto Bassi ${ }^{1}$ \\ Patrícia da Silva Cecim²
}

Maúcha Sifuentes dos Santos ${ }^{3}$

\section{RESUMO}

Este trabalho objetivou conhecer as situações que se apresentam ao estudante de Medicina como angustiantes durante a sua formação e os fatores que ele identifica como originários desse sentimento. Foi empregada uma abordagem etnográfica, utilizando-se entrevistas semi-estruturadas, observação e grupos de discussão. Os dados foram analisados por meio de Análise de Conteúdo. Os alunos identificaram a dissociação entre o ciclo básico e o profissionalizante como responsável pela angústia suscitada em face do primeiro contato com o paciente, além de apresentarem estresse psicológico por terem que trabalhar com a dor e o sofrimento. Os discentes identificaram, também, como fator estressante o fato de que sua aprendizagem implica a utilização de outro ser humano. Além disso, em algumas situações, a dificuldade de relacionamento com os professores é apontada como geradora de angústia.

\begin{abstract}
The aim of this study was to learn what kind of situations medical students perceive as distressing in the course of their undergraduate studies, and to which factors they attribute this sensation of distress. To this purpose an ethnographic approach using semi-structured interviews, observations, and discussion groups was employed. The collected data were analyzed by Content Analysis. The students identified the gap between basic medical education and the part of the course which emphasizes general clinical practice - the first contact with the patient and the psychological stress provoked by having to deal with pain and suffering - as responsible for their distress. Another stress-factor identified by the students is the awareness that their learning process implies in "using" another human being. Difficult relationships with the professors in certain situations were also indicated as causing distress.
\end{abstract}

\footnotetext{
${ }^{1}$ Universidade Federal de Santa Maria, Rio Grande do Sul, Brasil.

${ }^{2}$ Hospital Universitário de Santa Maria. Universidade Federal de Santa Maria, Rio Grande do Sul, Brasil.

${ }^{3}$ Universidade Federal do Rio Grande do Sul, Rio Grande do Sul, Brasil.
} 


\section{INTRODUÇÃO}

Os estudantes de Medicina passaram por um vestibular que apresenta um dos mais altos índices de candidatos por vaga das universidades do Brasil. Eles são os futuros formandos de uma profissão idealizada pela população, tanto em relação ao êxito econômico que se acredita que ela venha a possibilitar, como por um certo glamour que a rodeia. Conforme Oliveira e Ismael 1 , "a imagem mais associada ao médico, quase que um estereótipo, é a do herói conquistando a morte...". Tudo isso faria supor a existência de um alto grau de satisfação entre os estudantes de Medicina. Contudo, diversos trabalhos apontam a presença de depressão e angústia entre esses estudantes ${ }^{2-7}$.

Observa-se que os diferentes cursos de Medicina apresentam grande interesse na aprendizagem de seus alunos, gerando um aprimoramento nas formas de intervenção, além de atualização em relação a novas técnicas e melhoria das equipes profissionais. Mas essa mesma inquietação não se evidencia em relação à saúde mental de seu educando ${ }^{8}$. O resultado é a formação de um estudante que, nos semestres finais do curso, tem conhecimentos sobre as diferentes áreas biomédicas, mas apresenta deficiências no relacionamento com o ser humano que tem à sua frente, embora a eficácia de sua abordagem dependa, também, desse fator ${ }^{9}$.

Existe ainda outra situação: tanto o profissional como o estudante, ao entrarem em contato com seu paciente, ficam diante de sua própria vida, seus conflitos e frustrações. Essa situação pode favorecer o surgimento de mecanismos rígidos de defesa, com conseqüências tanto na sua profissão como na sua vida pessoal $^{10}$.

Devido ao alto grau de conflitos presentes no curso em função do convívio constante com a morte, a dor e o sofrimento, a educação médica produz estresse em níveis que podem ser prejudicais ao bem-estar físico e psicológico do estudante ${ }^{11}$. Tais conflitos estão vinculados, também, às expectativas que os alunos têm ao ingressarem no curso. Eles esperam, por meio de sua formação, conseguir ajudar aqueles que solicitem sua intervenção. Contudo, a prática num hospital de ensino logo os remete a uma realidade que frustra essas expectativas, pois, em muitos casos, não existem mais possibilidades de reverter o quadro clínico em função do estágio avançado da patologia. Em outros casos, por sua vez, os problemas apresentados pelos pacientes extrapolam a esfera da medicina, estando diretamente vinculados a problemáticas sociais. Desse modo, o aluno se vê colocado diante de uma realidade que estilhaça suas ilusões onipotentes ${ }^{12}$.

$\mathrm{O}$ aspecto emocional, muitas vezes, é negligenciado na formação do estudante de Medicina por se acreditar que, caso se manifestasse, seria prejudicial ao desempenho acadêmico. Essa perspectiva leva a uma tentativa de eliminar as emoções, com o objetivo de que elas não interfiram no futuro trabalho profissional ${ }^{13-15}$. Porém, a necessidade do aluno de lidar sozinho com a angústia gerada na sua formação causa um prejuízo em sua aprendizagem ${ }^{12}$.

Tem-se tratado muito sobre como o paciente é submetido a um processo de despersonalização ao entrar num hospital 16-18. Mas essa mesma preocupação com os aspectos humanos não parece ser tão intensa quando o sujeito é o estudante de Medicina.

$\mathrm{Na}$ atualidade, diversas universidades dispõem de serviços de apoio ao estudante, objetivando a saúde mental do discente ${ }^{19,20}$. Contudo, acredita-se que uma compreensão melhor dos fatores identificados como geradores de angústia entre os estudantes de Medicina possa vir a colaborar para o melhor desempenho no processo de humanização dos cursos de Medicina.

Surge, assim, uma inquietação que norteou o presente trabalho: quais os fatores identificados como geradores de angústia entre os alunos de Medicina?

\section{MÉTODO}

Para alcançar o objetivo proposto, optou-se por uma abordagem qualitativa, empregando-se a pesquisa etnográfica ${ }^{21,22}$. Foram utilizadas as técnicas de entrevistas semi-estruturadas, observação participante e grupos de discussão num curso de Medicina de uma universidade federal.

As entrevistas abordaram pontos identificados como eixos norteadores do trabalho, como situações que acarretam estresse no estudante ou problemáticas emocionais ou circunstâncias que o estudante tenha vivenciado ou presenciado nas quais se apresentaram essas situações; como as mesmas foram elaboradas; se existiu ajuda por parte do curso ou da instituição hospitalar; se essas problemáticas foram discutidas entre os colegas de curso ou com os professores. Esses eixos se tornaram necessários, pois, "na verdade, nenhuma interação, para finalidade de pesquisa se coloca de forma totalmente aberta" 23 .

O grupo de entrevistados foi composto de uma amostra do tipo intencional, sendo escolhidos aqueles estudantes que durante a observação: 1) entraram em contato com algum paciente que tivesse falecido ou que não apresentasse perspectivas de cura; 2) deram informações sobre o estado de terminalidade a pacientes ou a seus familiares; 3) demonstraram algum tipo de preocupação nas aulas de anatomia (referências a mal-estar de forma explícita - sudoreses, tonturas, fraqueza nos membros inferiores, pressão baixa, falta de ar, manifestações identificadas como síndrome vagal - ou por meio de chistes em relação ao cadáver ou peças anatômicas); 
4) manifestaram, durante as aulas observadas, algum tipo de preocupação relacionada à sua formação ou à prática médica. Obteve-se um total de 11 entrevistas, sendo sete estudantes do sexo feminino e quatro do sexo masculino, de diversos semestres do curso, com idades entre 18 e 27 anos.

As observações, não estruturadas, foram realizadas nas UTIs e no Pronto Atendimento de um hospital-escola, lugares freqüentados por estagiários do quinto ao décimo semestre, bem como nas aulas de Clínica Médica I (quinto semestre) e de Anatomia Geral (primeiro semestre). Nas UTIs e no Pronto Atendimento, o pesquisador permaneceu no setor por dois turnos semanais pelo período de um mês. Na observação desenvolvida nas aulas das disciplinas mencionadas, o professor responsável pela disciplina explicou a presença do pesquisador, que solicitou o consentimento dos alunos. Foram observadas todas as aulas de Anatomia e metade das aulas de Clínica Médica I. As observações foram registradas num diário, sendo essas anotações tanto descritivas como analíticas ${ }^{23}$.

Os grupos de discussão foram compostos por um coordenador do grupo e um auxiliar, tendo um máximo de dez e um mínimo de oito membros participantes. Foram realizados três grupos: o primeiro com estudantes do primeiro semestre, o segundo com estudantes do quinto semestre e o terceiro com estudantes do décimo primeiro semestre. As discussões foram gravadas em áudio com o prévio consentimento de seus integrantes e, posteriormente, transcritas e analisadas. Como forma de provocar a discussão, foi apresentada uma situação motivadora referente à temática em questão e solicitadas opiniões sobre ela.

Os grupos de discussão complementaram a observação e as entrevistas, pois neles o papel prioritário foi desempenhado pelas opiniões, relevâncias e valores de seus componentes, enquanto na observação o foco recaiu sobre comportamentos e relações. Os grupos de discussão permitiram, também, esclarecer temáticas que surgiram na observação e nas entrevistas individuais devido à interação de seus membros. Com efeito, acredita-se que a interação presente nos grupos possibilitou a visualização de novas formas de interpretação da problemática abordada ${ }^{24}$.

Os dados assim obtidos foram tratados com emprego da análise de conteúdo ${ }^{25}$, método de reconhecida importância nas pesquisas qualitativas ${ }^{26}$, uma vez que possibilita visualizar os diferentes sentidos (manifestos e latentes) das falas dos sujeitos da pesquisa ${ }^{23}$. Após a "leitura flutuante" do material coletado, foram categorizados os tópicos emergentes "segundo os critérios de relevância e repetição ${ }^{26 \text { ", }}$ resultando nas seguintes categorias: o ciclo básico; as aulas de anatomia; o contato com o paciente; a aprendizagem por meio do paciente; a identificação com o mestre.
Antes de se realizar o trabalho, o projeto foi submetido à Comissão de Pesquisa do Centro de Ciências Sociais e Humanas da UFSM e ao Colegiado do Curso de Medicina no qual a pesquisa foi desenvolvida.

\section{RESULTADOS E DISCUSSÃO}

\section{O ciclo básico}

Tanto nas entrevistas como nas observações, observou-se uma grande insatisfação por parte dos alunos com os dois primeiros anos do curso. Esse período inicial é visto como um momento de sua formação no qual adquirem um conhecimento meramente teórico. Essa crítica em relação à dissociação entre o ciclo básico (os dois primeiros anos do curso) e o profissionalizante faz-se presente no corpo discente, independentemente do ano que está sendo cursado.

[...] que faltam muitas aulas práticas que a gente, no caso, fica naquela parte teórica e não tem muita relação ainda com pessoas. Tá certo que é início de curso, mas a gente esperava, pelo menos, ter uma noção maior (estudante sexo masculino, primeiro semestre, grupo de discussão).

O ensino é diferente, as matérias dos dois primeiros anos do básico, eles(...) ensinam, só que sem associar com uma patologia, sem associar um caso clínico, jogam isso e é isso, só que daí(...) tu vai precisar mais adiante, mas com essa associação, que tu não tem, tu não[...] (estudante sexo feminino, $11^{\circ}$ semestre, grupo de discussão).

Esse aspecto pode ser constatado observando-se o currículo vigente no momento da realização da pesquisa*. Aliás, essa estruturação do curso de Medicina em três momentos - básico, clínico e internato - existe desde a criação da primeira faculdade brasileira, há mais de 180 anos $^{28}$. Conforme Radcliffe e Lester ${ }^{29}$, esse tipo de organização gera no curso uma dissociação reconhecida pelo aluno como uma das fontes de angústia.

Essa estrutura na qual o mais próximo que o estudante chega de uma pessoa, nos primeiros anos, é durante o contato com o cadáver nas aulas de Anatomia não pode deixar de ter influências no futuro relacionamento estudante-paciente ${ }^{12,30-34}$.

\section{As aulas de Anatomia}

Na denominação peça anatômica, a desumanização se faz presente ao transformar um cadáver - corpo sem vida, de alguém que já foi um ser humano - num objeto de estudo. Ainda assim, a lembrança de que esse corpo já foi uma pessoa

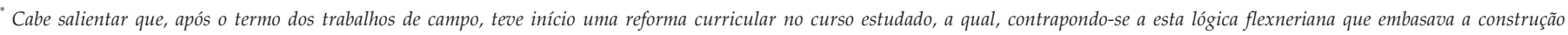
da grade curricular no momento da pesquisa, propunha um modelo alternativo, muito mais próximo do Paradigma da Integralidade ${ }^{27}$. 
permanece, gerando no estudante mal-estar e angústia ${ }^{35,36}$. Contudo, esse mal-estar não é explicitado, o desconforto emerge de forma encoberta em conversas paralelas durante o trabalho, em torno das mesas de dissecação:

[...] eu não como carne vermelha desde aquele dia, eu só como carne de galinha(...) no dia eu tinha medo de dormir (estudante sexo masculino, primeiro semestre, observação aula de Anatomia).

O chiste já foi identificado como uma forma de reduzir a angústia ${ }^{37}$. Assim, considera-se que o grande número de piadas nas aulas, tendo como tema o cadáver, pode ser visto como uma forma de reduzir a tensão:

Dá para fazer uma jaqueta de couro [referindo-se à pele de um cadáver] (estudante sexo feminino, primeiro semestre, observação aula de Anatomia).

Essa ambigüidade entre um mal-estar interno que não pode ser demonstrado e a realização de brincadeiras manifestando uma suposta descontração foi identificada também no trabalho de Valente e Boemer ${ }^{38}$, no qual as piadas são consideradas como uma forma de fugir do medo e assim conjurar a morte.

Não se deve esquecer que, no ciclo básico, énessa disciplina que o aluno se sente mais próximo de ser um médico, é nela que se veste debranco, usa luvas e tem a prerrogativa, negada a outras profissões, de retalhar cadáveres ${ }^{39}$. Além disso, a disciplina de Anatomia passa a ser um teste da personalidade do aluno ao defrontá-lo com a morte. É no espelho da postura do professor, imune tanto ao odor do formol, como às emoções, que o aluno procurará encontrar o caminho para trabalhar com esse turbilhão de sentimentos ${ }^{40}$.

\section{O contato com o paciente}

Será somente no terceiro ano que o aluno irá se defrontar com um sujeito que fala, pergunta, questiona comportamentos. Essas situações são geradoras de angústiano estudante durante o seu primeiro contato com o paciente.

A falta de vinculação das aulas com a prática, já assinalada, é vista como a responsável pela falta de preparo que os alunos apresentam ao iniciarem o contato com os pacientes:

[...] entra na clínica e tem que lidar direto com o paciente sem ter uma experiência, um paciente malhumorado,... é bem problemático isso pra nós (estudante sexo masculino, primeiro semestre, grupo de discussão).
Autores como Rocco ${ }^{41}$ e Sayd ${ }^{40}$ já assinalaram o desgaste emocional que acarreta ao estudante a sua inserção no hospital por meio da disciplina de Clínica Médica. Nesse momento, o aluno vai se deparar com um paciente que é um sujeito ativo, que tem uma idéia de sua doença e uma expectativa de tratamento, mas, principalmente, é um sujeito que padece. Isso deixa o estudante desorientado sobre como agir. Assim, essa falta de preparo sentida pelo estudante faz com que esse momento tão esperado, o do seu primeiro contato com o paciente, se torne uma experiência, avaliada pelo discente, como negativa e frustrante.

A paciente contou que o irmão tinha matado a mulher e logo se matado e começou a chorar. Eu não sabia se continuava falando disso ou mudava de assunto. Nós não sabemos como lidar com aquilo. E se a paciente se descontrolar? Vamos ficar indagando, mas depois não vamos poder ajudar (estudante sexo feminino, quinto semestre, grupo de discussão).

\section{A aprendizagem por meio do paciente}

O que aqui se faz presente é uma característica do processo de formação em Medicina: a de que o seu objeto de estudo é seu semelhante. Isso traz duas conseqüências: a primeira é a possibilidade da identificação do aluno com as patologias que ele estuda; e a segunda é que sua aprendizagem prática exige o "uso" do paciente. Desenvolve-se a seguir o primeiro item.

Como mencionado, essa identificação se inicia nas aulas de Anatomia, mas será no estudo das patologias que terá continuidade e ressurgirá como uma fonte de angústia, aspecto também assinalado por Gonçalves ${ }^{12}$.

A gente fica meio hipocondríaco. Fico com medo de ficar doente ou que meus familiares fiquem doentes (estudante sexo masculino, quinto semestre, entrevista).

No entanto, a grande fonte de angústia, e talvez uma das grandes dificuldades no ensino da Medicina, parece estar relacionada à necessidade de aprender com o paciente. De fato, o primeiro encontro do estudante com o paciente, por meio da anamnese, implica um constrangimento para o acadêmico, pois é visto como uma invasão da privacidade de uma pessoa com a qual não existe um relacionamento anterior. Por outro lado, o próprio exame clínico, através da exposição do corpo, coloca em xeque as noções de pudor e recato do estudante ${ }^{12}$.

Tal angústia, além de estar relacionada aos aspectos citados, vincula-se ao fato de que esses contatos iniciais não são vistos como uma relação de troca com o paciente e, sim, como o "uso" 
do mesmo, que passa a ocupar o lugar de objeto de aprendizagem do estudante. Por vezes, isso gera o sentimento de usar um ser humano que está padecendo para adquirir conhecimento sem dar alguma retribuição, originando, assim, sentimentos de culpa no estudante.

Essa sensação de uso do paciente foi constatada por Rocco ${ }^{41}$. $\mathrm{O}$ autor identificou, em seu estudo das vivências e sentimentos apresentados pelos estudantes durante as primeiras anamneses, que a grande maioria (119 em 120) revelou mal-estar por sentirse "usando" o paciente sem lhe dar nada em troca.

Na presente pesquisa, ficou evidente, também, a presença de angústia diante da realização das primeiras anamneses. Ao comentar as anamneses realizadas na disciplina de Propedêutica, uma estudante conta:

[...] e tem todos os 52 alunos pra fazer aquilo, então, às vezes, o paciente respondeu aquilo umas dez vezes, fora o doutorando, o residente e o médico que está passando por ele, ele já não agüenta mais...e aqueles pacientes de internação prolongada... então, tem uns que olhavam pra gente e... fechavam o olho e faziam que estavam dormindo(...) (estudante sexo feminino, $11^{\mathrm{o}}$ semestre, entrevista).

Observa-se nesse depoimento que a discente não somente considera que sua intervenção não traz benefícios ao paciente, como também manifesta o sentimento de que a sua aprendizagem se torna um incômodo para ele. Isso coloca o aluno num conflito entre o desejo de aprender e a preocupação com seu semelhante.

Em face da angústia de ter que utilizar o paciente para aprender, o discente pode criar uma barreira afetiva, disfarçada de objetividade, como a demonstrada por um formando ao apresentar um colega do quinto semestre a uma paciente, para aquele realizar uma anamnese:

Para a senhora não vai servir para nada, mas ele tem que aprender (estudante sexo masculino, sexto semestre, observação aula de Clínica Médica I).

Assim, como aponta Ribeiro ${ }^{34}$, os alunos podem passar a não identificar os pacientes do hospital ou do ambulatório onde realizam suas atividades práticas como sendo "seus pacientes" e, sim, como "um objeto de aprendizagem".

Além disso, foram identificadas outras situações em que, embora existisse angústia, esta não era manifestada explicitamente. Em diversos momentos, os alunos lançavam mão de brincadeiras como forma de aliviar a tensão quando se tornava necessário o "uso" do paciente como forma de aprendizagem. Por exemplo: após escutar os relatos dos estudantes, o professor escolhe um dos casos para verificar com os alunos. Nessa situação, foi selecionada uma paciente de cerca de 50 anos que apresentava alterações à ausculta no pulmão esquerdo. Após o professor auscultar a paciente, pede a sua autorização para que os alunos também possam auscultá-la. Nesse momento, observou-se certo mal-estar por parte dos alunos, que ficaram constrangidos ao terem que fazer uma fila para realizar o exame. Essa tensão foi amenizada por meio de brincadeiras como: "Aqui passa o ônibus para a cidade?" (estudante sexo masculino, sexto semestre, observação aula de Clínica Médica I). Esse mal-estar crescia à medida que aumentava o número de alunos que tinham realizado o exame na paciente. Alguns deles, após realizá-lo, comentavam tê-lo finalizado sem conseguir perceber a diferença na ausculta em face do constrangimento sentido.

Essa peculiaridade da aprendizagem conduz a um questionamento: da contradição entre a necessidade de aprender e o uso do paciente para tal fim não se está construindo no aluno uma representação do paciente como um objeto? Não se estará assim desumanizando o paciente e, conseqüentemente, o futuro médico? Deve-se levar em consideração que esses são os primeiros contatos que o discente estabelece com os pacientes e que, por conseguinte, são fundamentais para a construção do tipo de relacionamento que depois será adotado. Como é impossível prescindir dessa forma de aprendizagem, considera-se que a saída seja valorizar a discussão sobre os sentimentos que isso provoca.

Outra variante dessa situação conflitante apresenta-se no aprendizado de procedimentos invasivos, pois neles o estudante deve aprender tomando um ser humano como um objeto com o qual treinará. Não é possível treinar tais procedimentos em pessoas vivas em virtude do risco envolvido, nem com cadáveres após certo tempo do óbito ter acontecido, pois neles se estabelece o rigor mortis. Desse modo, a alternativa mais viável é o treino com pessoas recém-falecidas. Esse procedimento gera no estudante um conflito ético que, por vezes, o impede de realizar essa prática. $\mathrm{Ou}$, quando a realiza, sente que cometeu uma violência tanto em relação à pessoa falecida como contra ele mesmo. É importante destacar que, embora esse procedimento seja comum durante a formação, não é uma metodologia oficial de aprendizagem.

Eu particularmente não gosto... não me sinto muito à vontade, já, já fiz mas não, não... Ai, não sei, não... não gosto, assim, a pessoa já... já tá morta, ah, eu não sei, não sei explicar, mas eu não gosto, particularmente eu não gosto, eu não gostaria que fizessem isso com um familiar meu depois dele estar morto... É que, infelizmente, é a única maneira (estudante sexo feminino, $11^{\mathrm{o}}$ semestre, grupo de discussão). 
Concordamos com Zaidhaft ${ }^{36}$ quando sustenta que, nessas situações, os estudantes se sentem como sanguessugas ou, mais apropriadamente, urubus ao se nutrirem daqueles que até segundos antes eram seus pacientes ${ }^{35}$. Assim, é exigido do aluno que transgrida proibições fortemente arraigadas no seu grupo social e familiar, embora não haja ações pedagógicas que lhe dêem sustento para esse comportamento.

\section{A figura do mestre}

Os alunos expressam, por vezes, uma revolta diante do que consideram uma atitude autoritária da parte do professor para com eles. Essa atitude parece ser semelhante àquela relatada por pacientes em relação à falta de escuta por parte do seu médico; ou ainda, à situação descrita por Boltanski ${ }^{42}$ em que o médico inibe a capacidade de expressão do paciente ao desqualificar sua fala.

Tem alguns professores que o método de ensino é humilhar o aluno na frente de todos, na frente do paciente... tem outros que são mais camaradas, que existem certos sentimentos paternalistas (...). Que é dificil assim, às vezes a gente passa por períodos muito constrangedores no curso assim, nos rounds [passagem da equipe médica pelos leitos dos pacientes para realizar as revisões dos casos]. ... às vezes, usam termos inadequados para se relacionar com o aluno, por exemplo, (...) entrega o instrumento errado na cirurgia, ali, tem professores que dizem 'você vai ser médico ou vai ser padeiro?' Sabe, (...) humilham o aluno mesmo... (estudante sexo masculino, $11^{\circ}$ semestre, entrevista).

Ainda que esse tipo de professor seja identificado como uma minoria dentro do curso, essas situações deixam fortes marcas nos estudantes. Com efeito, esse tipo de comportamento desestimula os questionamentos e as dúvidas, fortalecendo uma aprendizagem baseada na repetição da conduta do mestre. Quando a temática em questão é a forma de se relacionar com o paciente ou com o familiar, o ensino parece limitar-se apenas à demonstração, por parte do professor, da conduta a ser adotada, prescindindo de orientações verbais. Acredita-se, assim, que essa aprendizagem implícita é a forma de transmitir as normas de conduta da relação médico-paciente.

É nesse sentido que Boulos ${ }^{43}$ afirma que a formação médica consiste numa ação muito mais ampla do que aprender conhecimentos relativos a processos biológicos e terapêuticos; ela "envolve a compreensão de regras sobre sentimentos, erros e manuseio de nossas falhas; em outras palavras, está relacionada à aquisição de caráter e identidade de médico".

\section{CONCLUSÃO}

Considera-se que as conseqüências de lidar cotidianamente com a morte e ter o semelhante como objeto de estudo poderiam ser minimizadas com a criação de espaços de discussão nos quais as emoções decorrentes da formação possam ser compartilhadas. Em disciplinas como Psiquiatria I e Introdução à Psiquiatria, nas quais são abordados aspectos psicológicos, seria recomendável enfatizar as emoções geradas no discente em função de sua formação, não somente de forma teórica, mas, por meio de observação e apresentação de casos, propiciando uma aproximação do discente com pessoas em diferentes fases do desenvolvimento.

Completando a afirmação anterior, outro modo de prevenir a negação das emoções como forma de defesa contra a angústia seria que as disciplinas específicas da formação não se limitassem a abordar os aspectos biológicos dos pacientes e incluíssem, também, os componentes emocionais que o contato com a doença, o sofrimento e a morte gera no estudante. Para esta finalidade é interessante sugerir, ainda, atividades de tutoria e ensino em pequenos grupos como formas de favorecer a emergência das emoções e a possibilidade de reflexão, o que reforça estudos como o de Saadeh ${ }^{4}$ e o trabalho de Marco $^{9}$.

Finalmente, considera-se que, por ser o processo de identificação com o professor um fator relevante na formação do estudante e na maneira como ele lidará com os fatores estressantes inerentes a sua profissão, torna-se necessário um investimento no corpo docente como forma de melhorar os modelos com base nos quais os alunos constroem sua identidade profissional.

\section{REFERÊNCIAS}

1. Oliveira MFP, Ismael SMC, orgs. Rumos da psicologia hospitalar em cardiologia. Campinas, SP: Papirus; 1995.

2. Costa LSM, Mattos EC, Silva FL. A influência do curso de medicina da Universidade Federal Fluminense na qualidade de vida dos seus estudantes. Rev Bras Educ Med. 2001; 25(2): 7-14.

3. Hays LR, Cheever T, Patel P. Medical student suicide, 19891994. Am J Psychiatry. 1996; 153(4): 553-5.

4. Meleiro AMAS. Suicídio entre médicos e estudantes de medicina. Rev Ass Med Brasil. [online]. 1998 [capturado 16 jul. 2001]; 44(2). Disponível em: http:/ / www.scielo.br.

5. Millan LR, Rossi E, Marco OLN. O suicídio entre os estudantes de medicina. In: Universidade de São Paulo. Centro de Desenvolvimento da Educação Médica. Assistência psicológica ao aluno de medicina. São Paulo: USP; 1994. p.35-54.

6. Millan LR, Rossi E, Marco OLN. A psicopatologia do estudante de Medicina. In: Millan LR, Rossi E, Marco OLN, Arruda PCV, 
orgs. O Universo psicológico do futuro médico: vocação, vicissitudes e perspectivas. São Paulo: Casa do Psicólogo; 1999. p.83-101.

7. Supe AN. A study of stress in medical students at Seth G.S. Medical College. J Postgrad Méd. 1998; 44(1): 1-6.

8. Bromberg MHPF. Cuidados paliativos para o paciente com câncer: uma proposta integrativa para a equipe, paciente e famílias. In: Carvalho MMJ. Psico-oncologia no Brasil: resgatando o viver. São Paulo: Summuns; 1998. p.187-231.

9. Marco OLN. Grupos de reflexão com quintanistas de Medicina. In: Millan LR, Rossi E, Marco OLN, Arruda PCV, orgs. O Universo psicológico do futuro médico: vocação, vicissitudes e perspectivas. São Paulo: Casa do Psicólogo; 1999. p.129-138.

10. Martins MCFN. Humanização das relações assistenciais: a formação do profissional de saúde. São Paulo: Casa do Psicólogo; 2001.

11. Lee J, Graham AV. Student's perception of medical school stress and their evaluation of a wellness elective. Med Educ. 2001; 35(7): 652-9.

12. Gonçalves EL. De ingressante na faculdade a médico especialista: uma longa trajetória. In: Marcondes E, Gonçalves EL. Educação médica. São Paulo: Sarvier; 1998. p.325-339.

13. Quintana AM, Arpini DM. A atitude diante da morte e seus efeitos no profissional de saúde: uma lacuna da formação? Psicol Argum. 2002; 19(30): 45-50.

14. Quintana AM, Cecim PS, Henn CG. O preparo para lidar com a morte na formação do profissional de medicina. Rev Bras Educ Med. 2002; 26(3): 204-10.

15. Quintana AM, Rodrigues AT, Goi CMD, Bassi L A. Humanização e estresse na formação médica. Rev AMRIGS. 2004; 48(1): 27-31.

16. Camon VAA. O psicólogo no hospital. In: Camon VAA, Trucharte FAR, Knijnik RB, Sebastiani RW. Psicologia hospitalar: teoria e prática. São Paulo: Pioneira; 2001. p.15-28.

17. Goffman E. Manicômios, prisões e conventos. 6 ed. São Paulo: Perspectiva; 1999.

18. Pitta A. Hospital: dor e morte como ofício. São Paulo: Hucitec; 1999.

19. Cianflone ARL, Figueiredo JFC, Colares MFA. O Centro de Apoio Educacional e Psicológico (CAEP) da Faculdade de Medicina de Ribeirão Preto (USP): história e perspectivas. Medicina (Ribeirao Preto). 2002; 35(3): 392-6.

20. Ramos-Cerqueira ATA, Lima MCP, Torres AR, Reis JRT, Fonseca NMV. Era uma vez... contos de fadas e psicodrama auxiliando alunos na conclusão do curso médico. Interface. 2004-2005; 9(16): 81-9.
21. Laville C, Dione J. A construção do saber: manual de metodologia da pesquisa em ciências humanas. Porto alegre: Artmed; 1999.

22. Strauss A, Corbin J. Basics of qualitative research: graunded theory procedures and techniques. London: Sage; 1990.

23. Minayo MCS. O desafio do conhecimento: pesquisa qualitativa em saúde. 4 ed. São Paulo: Hucitec; 1996.

24. Jovchelovitch S. Representações sociais e esfera pública: a construção simbólica dos espaços públicos no Brasil. Petrópolis, RJ: Vozes; 2000.

25. Bardin L. Análise de conteúdo. Lisboa: Edições 70; 1977.

26. Turato ER. Tratado da metodologia da pesquisa clínicoqualitativa: construção teórico-epistemológica, discussão comparada e aplicação nas áreas da saúde e humanas. Petrópolis, RJ: Vozes; 2003.

27. Lampert JB. Tendências de mudanças na formação médica no Brasil: tipologia das escolas. São Paulo: Hucitec; 2002.

28. Millan LR. O curso médico no Brasil. In: Millan LR, Rossi E, Marco OLN, Arruda PCV, orgs. O universo psicológico do futuro médico: vocação, vicissitudes e perspectivas. São Paulo: Casa do Psicólogo; 1999. p.31-42.

29. Radcliffe $C$, Lester $H$. Perceived stress during undergraduate medical training: a qualitative study. Med Educ. 2003;37(1):32-8.

30. Arruda PCV. As relações entre alunos, professores e pacientes. In: Millan LR, Rossi E, Marco OLN, Arruda PCV, orgs. O universo psicológico do futuro médico: vocação, vicissitudes e perspectivas. São Paulo: Casa do Psicólogo; 1999. p.43-74.

31. Dyer GS, Thorndike, MEL. Quidne mortui vivos docent? the evolving purpose of human dissection in medical education. Acad Méd. 2000; 75(10): 969-79.

32. Martins C. Perspectivas da relação médico-paciente. Porto Alegre: Artes Médicas; 1979. Cap.: Introdução: incidências contemporâneas na relação médico-paciente.

33. Perazzo S. O médico e a morte. Rev Psiquiatr Clin. 1985; 12(34): 96-100.

34. Ribeiro ECO. Ensino/aprendizagem na escola médica. In: Marcondes E, Gonçalves EL. Educação médica. São Paulo: Sarvier; 1998. p.40-49.

35. Carvalho VA. A vida que há na morte. In: Bromberg MHPF, Kovács MJ, Carvalho MMJ, Carvalho VA. Vida e morte: laços de existência. São Paulo: Casa do Psicólogo; 1996. p.35-75.

36. Zaidhaft S. Morte e formação médica. Rio de Janeiro: Francisco Alves; 1990.

37. Freud S. El chiste y su relación con lo inconsciente. In: Edição standard brasileira das obras psicológicas completas de Sigmund Freud. Rio de Janeiro: Imago; 1980. t.VIII. 
38. Valente SH, Boemer MR. A sala de anatomia enquanto espaço de convívio com a morte. Rev Bras Enfermagem. 2000; 53(1): 99-108.

39. Muniz JR, Chazan LF. Ensino de psicologia médica. In: Mello Filho J, org. Psicossomática hoje. Porto Alegre: Artes Médicas; 1992. p.37-44.

40. Sayd JD. A escola médica e seus implícitos sobre a morte. Rev Bras Educ Med. 1993; 17(3): 14-20.

41. Rocco RP. Relação estudante de Medicina-paciente. In: Mello Filho J, org. Psicossomática hoje. Porto Alegre: Artes Médicas; 1992. p.45-56.

42. Boltanski L. As classes sociais e o corpo. Rio de Janeiro: Graal; 1984.

43. Boulos M. Relação médico-paciente: o ponto de vista do clínico. In: Marcondes E, Gonçalves EL. orgs. Educação médica. São Paulo: Sarvier; 1998. p.50-57.
44. Saadeh A. Internato em medicina: estudo da interação estudante-paciente. São Paulo; 1995. Mestrado [Dissertação] - Universidade de São Paulo.

\section{CONFLITOS DE INTERESSE}

Declarou não haver.

\section{FINANCIAMENTO}

FAPERGS - Processo 01/0710.2

\section{ENDEREÇO PARA CORRESPONDÊNCIA}

Alberto M. Quintana

Rua Tiradentes, 23 - Apto 701

97050-730 - Santa Maria - RS

E-mail: albertoq@ccsh.ufsm.br 